\title{
PENGATURAN POLA TANAM METEOROLOGIS SEBAGAI SALAH SATU UPAYA OPTIMALISASI PRODUKTIVITAS PERTANIAN DI KAWASAN KARST KABUPATEN GUNUNGKIDUL
}

\author{
Ahmad Cahyadi' ${ }^{1}$, Henky Nugraha ${ }^{2}$, Fitria Nucifera ${ }^{3}$ \\ 1,2,3 Karst Student Forum (KSF) Fakultas Geografi Universitas Gadjah Mada \\ 1,2,3 Magister Perencanaan Pengelolaan Pesisir dan Daerah Aliran Sungai \\ (MPPDAS) Fakultas Geografi Universitas Gadjah Mada Yogyakarta \\ 1,2Jurusan Geografi Lingkungan Fakultas Geografi Universitas Gadjah Mada \\ Email: 1ahmadcahyadi@geo.ugm.ac.id
}

\section{INTISARI}

Pengaturan pola tanam meteorologis sangat penting dilakukan di kawasan karst Kabupaten Gunungkidul mengingat lahan pertanian yang dominan di kawasan tersebut adalah tegalan dan sawah tadah hujan yang sangat tergantung dengan adanya air dari hujan. Penelitian ini bertujuan untuk (1) mengetahui tipe iklim di kawasan karst Kabupaten Gunungkidul dan (2) menyusun pola tanam meteorologis berdasarkan catatan curah hujan yang ada di kawasan karst Kabupaten Gunungkidul. Satu stasiun hujan yang digunakan dalam penelitian ini akan memiliki satu tipe pola tanam. Metode yang digunakan untu menentukan tipe iklim dan pola tanam meteorologis adalah tipe iklim dan pola tanam meteorologis yang disusun oleh Balai Penelitian Agroklimat dan Hidrologi, Departemen Pertanian Republik Indonesia (2007). Hasil penelitian menunjukkan bahwa tipe iklim yang terdapat pada kawasan karst Kabupaten Gunungkidul terdiri dari tipe iklim IIA, IIC dan IIIB. Tipe iklim IIA dan IIC hanya mampu melakukan sekali panen dalam setahun, sedangkan pada wilayah dengan tipe iklim IIIB dapat melakukan panen sebanyak dua kali dalam setahun.

Kata Kunci : Karst, Pola Tanam Meteorologis, Tipe Iklim

\section{PENDAHULUAN}

Lahan pertanian di kawasan karst Kabupaten Gunungkidul didominasi oleh lahan kering, yakni berupa sawah tadah hujan dan tegalan (Sudarmadji dkk, 2012). Kondisi ini menyebabkan pengusahaan lahan pertanian di wilayah ini sangat tergantung pada curah hujan (Suryanti dkk, 2010). Meskipun demikian, beberapa tempat dapat mengusahakan tanah pertanian dengan mengandalkan air yang berasal dari mataair, seperti pada wilayah pertanian di Desa Giritirto, Kecamatan Purwosari. 
Kondisi pertanian yang hanya dapat memproduksi hasil pertanian pada musim kemarau, menyebabkan produktivitas lahan pertanian menjadi kecil. Selain itu, produktivitas lahan yang rendah juga disebabkan karena lahan di kawasan karst Gunungkidul lebih banyak didominasi oleh lahan yang tidak cocok untuk pertanian (kelas lahan VII dan VIII, meskipun pada dataran alluvial dapat memiliki kelas kemampuan lahan sampai dengan II)(Worosuprojo dkk, 1997; Cahyadi dkk, 2012). Kondisi demikian seringkali diperparah dengan pemilihan jenis tanaman yang sebenarnya tidak sesuai dengan kondisi lingkungan khususnya iklim, sehingga selain produktivitas pertanian menjadi rendah, seringkali petani mengalami kerugian akibat tanaman pertanian mati sebelum dapat dipanen.

Rendahnya pendapatan dari sektor pertanian akan menyebabkan terjadinya tekanan penduduk yang tinggi (Muta'ali, 2012). Hal ini kemudian akan menyebabkan daya dukung lingkungan terlampaui serta menyebabkan berbagai dampak dari aktivitas manusia yang dapat merudak lingkungan (Sartohadi dan Putri, 2008; Krisnohadi, 2011). Misalnya dengan melakukan perluasan lahan pertanian pada lahan-lahan marjinal yang didahului dengan penebangan hutan atau kayu-kayu di atas bukit dan membuat teras-teras untuk lahan pertanian. Kondisi demikian disampaikan pula dalam penelitian Sunkar (2008) dan Eiche (2011) yang menyampaikan bahwa telah terjadi deforestasi di kawasan karst Kabupaten Gunungkidul yang menyebabkan hilangnya vegetasi tanaman tahunan di bukit-bukit karst. Oleh karena itu, diperlukan upaya-upaya untuk dapat meningkatkan produktivitas pertanian di kawasan karst Kabupaten Gunungkidul, agar kelestarian lingkungan dapat terus dijaga.

Penelitian ini bertujuan untuk (1) mengetahui tipe iklim di kawasan karst Kabupaten Gunungkidul dan (2) menyusun pola tanam meteorologis berdasarkan catatan curah hujan yang ada di kawasan karst Kabupaten Gunungkidul. Satu stasiun hujan yang digunakan dalam penelitian ini akan memiliki satu tipe pola tanam. Pemisahan area yang terwakili oleh stasiun curah hujan dibatasi dengan polygon thiessen. Hasil penelitian ini diharapkan dapat digunakan untuk memberikan masukan dalam perencanaan pola tanam di kawasan karst Gunungsewu, sehingga produktivitas pertanian dapat dioptimalkan.

\section{METODE PENELITIAN}

Pola tanam meteorologis wilayah penelitian ditentukan dengan penentuan pola tanam meteorologis yang digunakan oleh Balai Penelitian Agroklimat dan Hidrologi, Departemen Pertanian Republik Indonesia (2007). Hal ini didasarkan pada kenyataan bahwa zona agroklimat memiliki kaitan yang sangat erat dengan dengan arahan pola tanam. Balai Penelitian Agroklimat dan Hidrologi, Departemen Pertanian Republik Indonesia (2007) 
menyebutkan bahwa dalam pembuatan agihan untuk pola tanam diperlukan agihan zona ketersediaan hujan. Klasifikasi curah hujan di Indonesia dapat dibagi menjadi beberapa kelas I-VI (Tabel 1).

Tabel 1. Klasifikasi Curah Hujan

\begin{tabular}{|c|c|}
\hline Kelas & Curah Hujan Tahunan (mm/thn) \\
\hline I & $<1000$ \\
\hline II & $1000-2000$ \\
\hline III & $2000-3000$ \\
\hline IV & $3000-4000$ \\
\hline V & $4000-5000$ \\
\hline VI & $>5000$ \\
\hline
\end{tabular}

Sumber : Balai Penelitian Agroklimat dan Hidrologi, Deptan, 2007

Penentuan zona agroklimat dalam rangka penyusunan arahan pola tanam yang ada harus memasukkan unsur pola curah hujan dalam penentuannya (Nurjani dkk, 2011). Pembagian pola curah hujan didasarkan pada metode Trejor (1976) dalam Balai Penelitian Agroklimat dan Hidrologi, Departemen Pertanian Republik Indonesia (2007) dengan modifikasi. Pembagian ini menghasilkan 4 (empat) klasifikasi pola curah hujan yang ada, yaitu :

1. Pola tunggal atau sederhana dengan curah hujan terendah pada Bulan Juli/Agustus, dengan notasi A.

2. Pola tunggal dengan curah hujan tertinggi pada Bulan Juli/Agustus, dengan notasi D.

3. Pola fluktuasi/ majemuk, diberi notasi B.

4. Pola ganda, notasi C.

Tabel 2. Tabel Agihan Iklim dan Pola Curah Hujan

\begin{tabular}{|c|c|c|c|c|c|c|}
\hline $\begin{array}{l}\text { Curah } \\
\text { Hujan } \\
\text { Tahunan } \\
\text { (mm/thn) }\end{array}$ & Pola & $\begin{array}{l}\text { Tipe } \\
\text { Iklim }\end{array}$ & $\begin{array}{c}\mathrm{CH} \leq 100 \\
(\mathrm{~mm} / \mathrm{bln})\end{array}$ & $\begin{array}{c}\text { CH 100- } \\
150 \\
(\mathrm{~mm} / \mathrm{bln})\end{array}$ & $\begin{array}{c}\text { CH 150- } \\
200 \\
\mathrm{~mm} / \mathrm{bln}\end{array}$ & $\begin{array}{c}\mathrm{CH}> \\
200 \\
\mathrm{~mm} / \mathrm{bln}\end{array}$ \\
\hline \multirow{3}{*}{$<1000$} & I A & \multirow{6}{*}{$\begin{array}{l}\text { Iklim } \\
\text { Kering }\end{array}$} & $7-10$ & $\leq 4$ & $\leq 3$ & $\leq 2$ \\
\hline & I B & & $8-12$ & $\leq 3$ & 0 & 0 \\
\hline & IC & & $\begin{array}{l}8-9 \\
\end{array}$ & $\leq 2$ & $\leq 2$ & $\leq 2$ \\
\hline \multirow{3}{*}{$1000-2000$} & II A & & $5-8$ & $\leq 3$ & $\leq 2$ & $\leq 4$ \\
\hline & II B & & $\leq 4$ & $\leq 5$ & $\leq 5$ & $\leq 4$ \\
\hline & II C & & $\leq 5$ & $\leq 5$ & $\leq 6$ & $\leq 5$ \\
\hline
\end{tabular}




\begin{tabular}{|c|c|c|c|c|c|c|}
\hline $\begin{array}{c}\text { Curah } \\
\text { Hujan } \\
\text { Tahunan } \\
\text { (mm/thn) }\end{array}$ & Pola & $\begin{array}{l}\text { Tipe } \\
\text { Iklim }\end{array}$ & $\begin{array}{c}\mathrm{CH} \leq 100 \\
(\mathrm{~mm} / \mathrm{bln})\end{array}$ & $\begin{array}{c}\text { CH 100- } \\
150 \\
\text { (mm/bln) }\end{array}$ & $\begin{array}{c}\text { CH 150- } \\
200 \\
\mathrm{~mm} / \mathrm{bln}\end{array}$ & $\begin{array}{c}\mathrm{CH}> \\
200 \\
\mathrm{~mm} / \mathrm{bln}\end{array}$ \\
\hline \multirow{3}{*}{$2000-3000$} & III A & \multirow{15}{*}{$\begin{array}{l}\text { Iklim } \\
\text { Basah }\end{array}$} & $\leq 6$ & $\leq 4$ & $\leq 5$ & $\leq 6$ \\
\hline & III B & & $\leq 4$ & $\leq 4$ & $\leq 5$ & $5-6$ \\
\hline & III C & & $\leq 4$ & $\leq 4$ & $\leq 5$ & $6-8$ \\
\hline \multirow{4}{*}{$3000-4000$} & IV A & & $\leq 2$ & $\leq 3$ & $\leq 4$ & $7-9$ \\
\hline & IV B & & $\leq 2$ & $\leq 3$ & $\leq 3$ & 8-11 \\
\hline & IV C & & $\leq 3$ & $\leq 4$ & $\leq 4$ & $7-9$ \\
\hline & IV D & & $\leq 1$ & $\leq 3$ & $\leq 5$ & $7-9$ \\
\hline \multirow{4}{*}{$4000-5000$} & $\mathrm{VA}$ & & $\leq 2$ & $\leq 2$ & $\leq 1$ & $7-9$ \\
\hline & V B & & 0 & 0 & $\leq 2$ & $9-12$ \\
\hline & $\mathrm{VC}$ & & $\leq 2$ & $\leq 3$ & $\leq 2$ & $8-12$ \\
\hline & V D & & 0 & 0 & $\leq 1$ & $10-12$ \\
\hline \multirow{4}{*}{$>5000$} & VI A & & 0 & 0 & $\leq 2$ & $10-12$ \\
\hline & VI B & & 0 & 0 & 0 & 12 \\
\hline & VI C & & $\leq 1$ & 1 & $\leq 2$ & 9 \\
\hline & VI D & & 0 & 0 & 0 & 12 \\
\hline
\end{tabular}

Sumber : Balai Penelitian Agroklimat dan Hidrologi, Deptan, 2007

Pola A dan D menggambarkan pola curah hujan yang mempunyai perbedaan jelas antara jumlah curah hujan pada musim hujan dengan kemarau. Pola B memberikan gambaran adanya perbedaan yang tidak jelas antara jumlah curah hujan pada musim hujan dan kemarau. Pada pola B, biasanya jumlah curah hujan tidak teratur pada tiap bulannya atau hampir sama sepanjang tahun. Pola $\mathrm{C}$ memberikan gambaran terjadi dua kali curah hujan terendah dalam setahun dengan satu puncak curah hujan dan dapat pula sebaliknya (Balai Penelitian Agroklimat dan Hidrologi, Departemen Pertanian Republik Indonesia, 2007). Metode penentuan agihan zona agroklimat dapat dilihat pada Tabel 2 .

Penentuan arahan pola tanam dilakukan dengan metode Balai Penelitian Agroklimat dan Hidrologi, Departemen Pertanian Republik Indonesia (2007). Metode ini didasarkan pada sebaran hujan yang ditentukan dengan agihan iklim dan pola curah hujan. Berdasarkan hal tersebut, maka dapat ditentukan arahan pola tanam berdasarkan kondisi iklim dan pola curah hujan. Arahan pola tanam dapat dilihat pada Tabel 3. 
Tabel 3. Arahan Pola Tanam

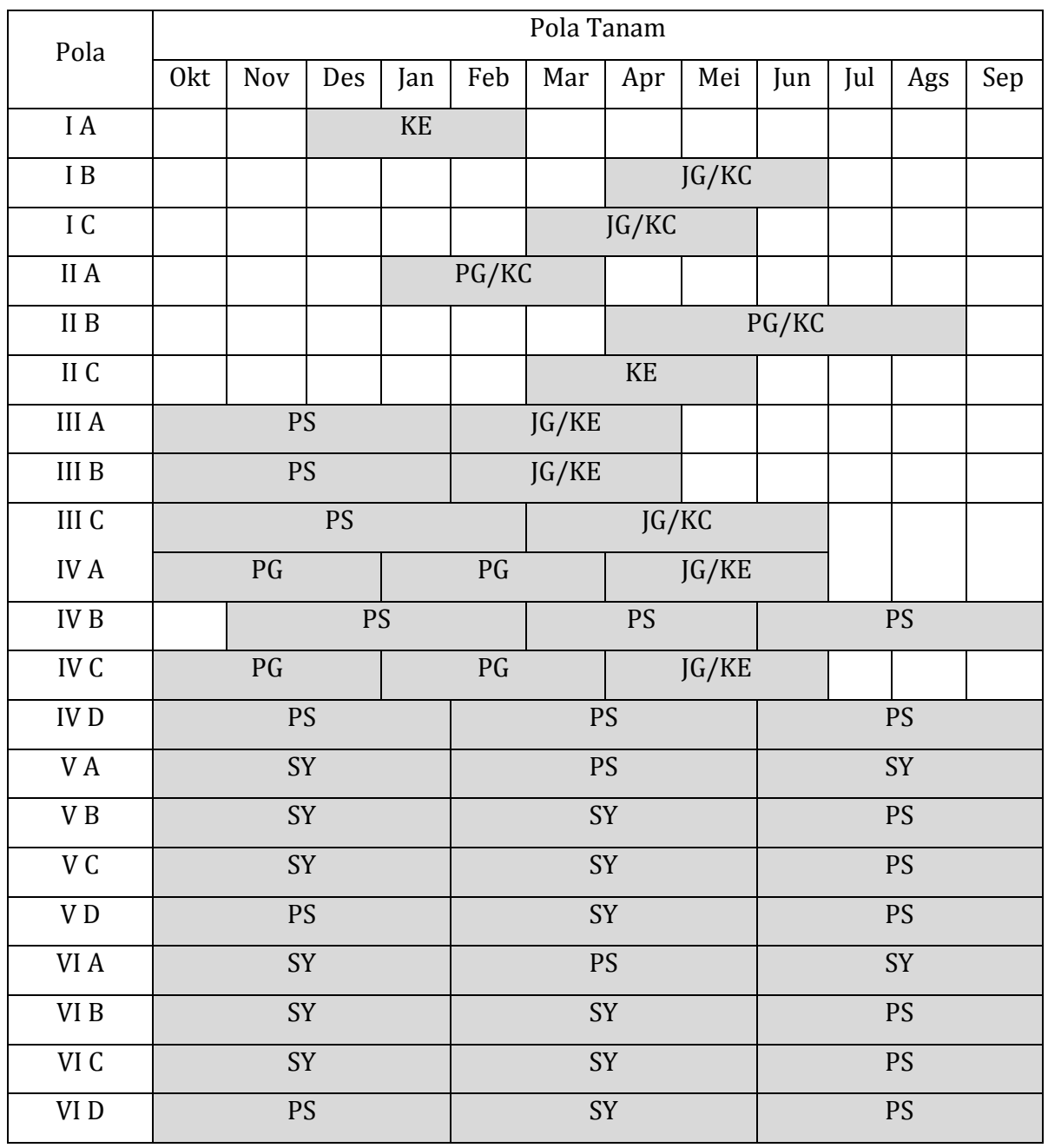

Sumber : Balai Penelitian Agroklimat dan Hidrologi, Deptan, 2007

Keterangan :

$\begin{array}{llllll}\text { PS } & : & \text { Padi Sawah } & \text { KE } & : & \text { Kedelai } \\ \text { KC } & : & \text { Kacang Tanah } & \text { JG } & : & \text { Jagung } \\ \text { PG } & : & \text { Padi Gogo } & \text { SY } & : & \text { Sayuran }\end{array}$




\section{HASIL DAN PEMBAHASAN}

Penelitian ini menggunakan 18 stasiun hujan yang terdapat di kawasan karst Gunungsewu dan sekitarnya. Penggunaan stasiun di luar kawasan karst dilakukan untuk dapat membandingkan hasil yang diperoleh di kawasan kasrt Gunungsewu dengan wilayah lain di sekitarnya. Stasiun hujan yang digunakan dalam penelitian ini ditunjukkan dalam Tabel 4.

Tabel 4. Stasiun Hujan, Koordinat Lokasi, Curah Hujan di Kawasan Karst Gunungsewu Kabupaten Gunungkidul

\begin{tabular}{|c|c|c|c|c|}
\hline \multirow{2}{*}{ Stasiun Hujan } & \multicolumn{2}{|c|}{ Koordinat Lokasi } & $\begin{array}{c}\text { Curah Hujan } \\
\text { (mm/Tahun) }\end{array}$ & $\begin{array}{c}\text { Tipe } \\
\text { Iklim }\end{array}$ \\
\cline { 2 - 3 } & $\mathbf{X}$ & $\mathbf{Y}$ & 1.455 & IIA \\
\hline Kedungkeris & 455908 & 9128023 & 1.295 & IIA \\
\hline Ngawen & 466621 & 9133191 & 1.635 & IIA \\
\hline Wonogomo & 453280 & 9123042 & 2.479 & IIIA \\
\hline Playen & 450402 & 9122459 & 1.945 & IIA \\
\hline Gantiwarno & 451300 & 9141564 & 1.660 & IIA \\
\hline Waduk Jombor & 459723 & 9142462 & 1.665 & IIA \\
\hline Kalijaran & 464838 & 9141403 & 1.880 & IIA \\
\hline Gedangan & 464976 & 9121922 & 1,126 & IIB \\
\hline Semin & 469837 & 9134272 & 1.790 & IIA \\
\hline Ponjong & 468024 & 9119051 & 1.790 & IIC \\
\hline Wonosari & 456069 & 9119839 & 2.053 & IIIB \\
\hline Panggang & 435171 & 9115074 & 1.535 & IIA \\
\hline Semanu & 462360 & 9115757 & 1.793 & IIA \\
\hline Paliyan & 447690 & 9115010 & 2.985 & IIIB \\
\hline Tepus & 459012 & 9105783 & 1.910 & IIC \\
\hline Rongkop & 471677 & 9105686 & 1.861 & IIC \\
\hline Pundong & 427136 & 9119801 & 2.019 & IIIA \\
\hline Terong & 441394 & 9124270 & & \\
\hline
\end{tabular}

Sumber: Hasil Analisis Data

Hasil analisis data hujan menunjukkan bahwa beberapa wilayah di kawasan karst Gunungsewu Kabupaten Gunungkidul memiliki curah hujan yang lebih tinggi dibandingkan dengan wilayah sekitarnya (Gambar 1). Namun demikian, secara umum curah hujan di kawasan karst Gunungsewu Kabupaten Gunungkidul relatif tidak terlalu berbeda dengan wilayah di sekitarnya. Kondisi ini menunjukkan bahwa fenomena kekeringan yang sering terjadi di wilayah ini lebih disebabkan karena kondisi litologis batuan dan hidrologis di kawasan karst Gunungsewu. 

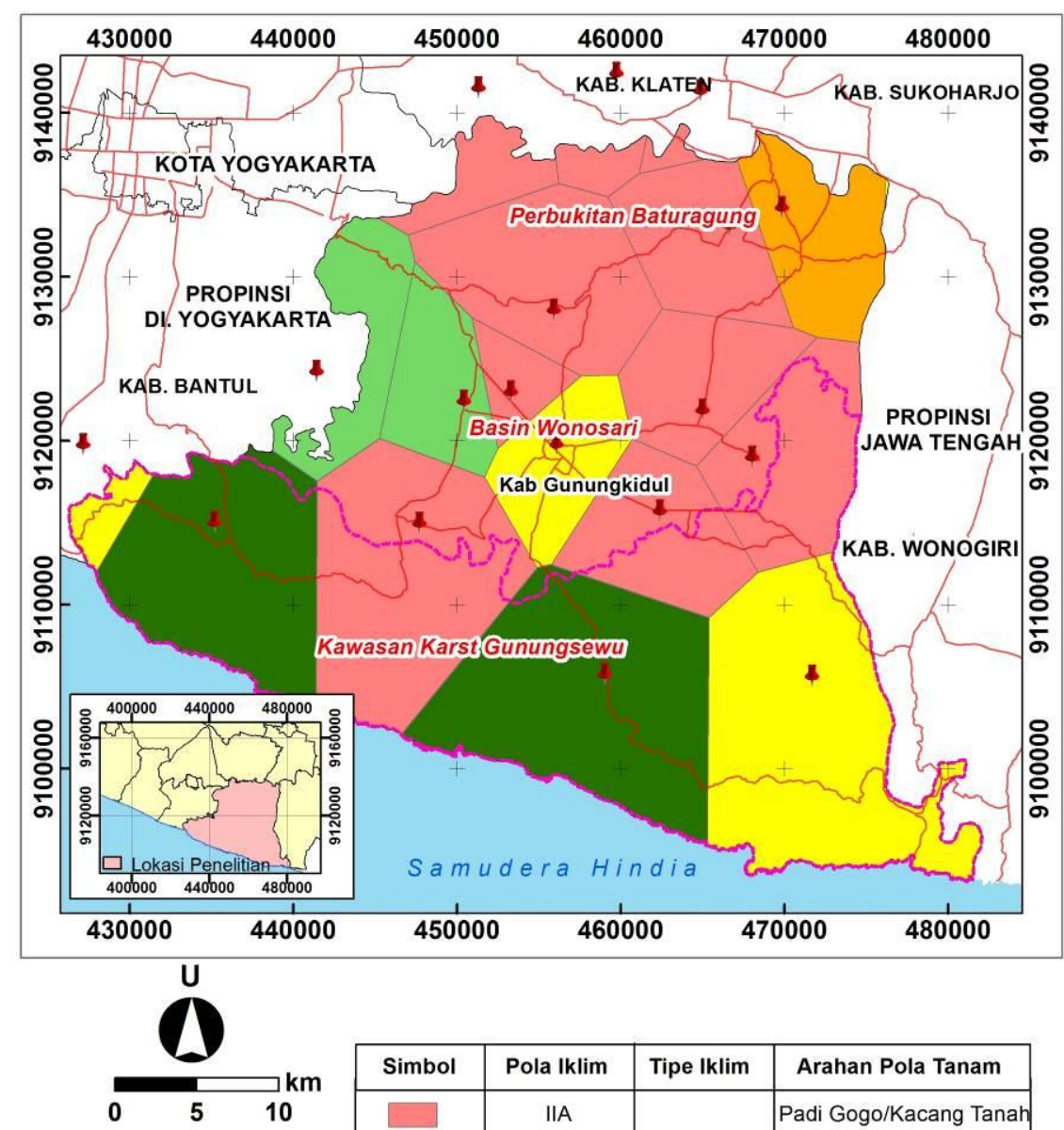

\begin{tabular}{|c|c|l|l|}
\hline Simbol & Pola Iklim & Tipe Iklim & Arahan Pola Tanam \\
\hline$\square$ & IIA & & Padi Gogo/Kacang Tanah \\
\hline & IIB & Iklim Kering & Padi Gogo/Kacang Tanah \\
Kedelai
\end{tabular}

Gambar 1. Peta Tipe Iklim Agrometeorologi di Kawasan Karst Gunungsewu Kabupaten Gunungkidul dan Sekitarnya 
Hasil analisis terhadap tipe iklim yang didasarkan pada curah hujan tahunan dan bulanan di wilayah kajian menunjukkan bahwa tipe iklim di kawasan karst Gunungsewu di Kabupaten Gunungkidul terdiri dari tipe iklim IIA, IIC dan IIIB (Tabel 5). Tabel 5 juga menunjukkan bahwa tipe iklim IIA dan IIC dapat melakukan panen sebanyak satu kali dalam setahun. Tipe IIA dapat melakukan penanaman padi gogo atau kacang pada Bulan April sampai dengan Juni, sedangkan wilayah dengan tipe iklim IIC dapat melakukan penanaman kedelai pada Bulan Juni samapai dengan Agustus. Hal yang agak berbeda terdapat di wilayah dengan tipe iklim IIB, di mana wilayah ini dapat melakukan dua kali panen dalam setahun. Penanaman dapat dilakukan pada Bulan Januari sampai dengan April dengan tanaman padi, sedangkan pada Bulan Mei sampai dengan Bulan Juli dapat dilakukan penanaman Jagung atau kedelai.

Tabel 5. Pola Tanam Berdasarkan Iklim Agrometeorologi di Kawasan Karst Gunungsewu Kabupaten Gunungkidul

\begin{tabular}{|c|c|c|c|c|c|c|c|c|c|c|c|c|}
\hline Pola & \multicolumn{12}{|c|}{ Bulan } \\
\hline & Jan & Feb & Mar & Apr & Mei & Jun & Jul & Agt & Sep & Okt & Nov & Des \\
\hline IIA & \multicolumn{3}{|c|}{ Bero } & \multicolumn{3}{|c|}{$\mathrm{PG} / \mathrm{KC}$} & \multicolumn{6}{|c|}{ Bero } \\
\hline II C & \multicolumn{5}{|c|}{ Bero } & \multicolumn{3}{|c|}{$\mathrm{KE}$} & \multicolumn{4}{|c|}{ Bero } \\
\hline III B & \multicolumn{4}{|c|}{ PS } & \multicolumn{3}{|c|}{$\mathrm{JG} / \mathrm{KE}$} & \multicolumn{5}{|c|}{ Bero } \\
\hline
\end{tabular}

Sumber: Hasil Analisis Data

Hasil penelitian yang diperoleh ternyata tidak sesuai dengan kondisi di lapangan. Pertama, Kondisi bulan basah di wilayah penelitian ternyata terjadi pada Bulan Oktober sampai dengan Bulan April (tipe monsun), namun demikian berdasarkan metode yang ada justru penenaman disarankan pada mulai pada Bulan April untuk tipe iklim IIA dan Bulan Juni tipe iklim IIC. Kedua, kondisi ini sangat tidak sesuai dengan kondisi yang berlaku dimasyarakat yang tergambar dari hasil penelitian yang dilakukan oleh (Awang dan Nurhadi, 2005) di mana masyarakat menanam ketela pohon yang memiliki umur panen selama 4-5 bulan. Ketiga, penanaman padi sawah tidak memungkinkan dilakukan karena sangat sedikit sekali lahan yang dapat digenangi. Berdasarkan kondisi tersebut, maka kemudian dilakukan modifikasi pola tanam seperti pada Tabel 6. Tabel 6 menunjukkan bahwa meskipun hanya dapat melakukan panen sebanyak satu kali dalam setahun, tetapi dengan adanya ketela pohon yang ditanam di awal musim, maka pada Bulan Maret atau April masih dapat dilakukan panen ketela pohon. 
Tabel 6. Pola Tanam Modifikasi Berdasarkan Iklim Agrometeorologi dan

Survei Lapangan di Kawasan Karst Gunungsewu Kabupaten Gunungkidul

\begin{tabular}{|c|c|c|c|c|c|c|c|c|c|c|c|c|}
\hline Pola & \multicolumn{9}{|c|}{ Bulan } \\
\hline & Okt & Nov & Des & Jan & Feb & Mar & Apr & Mei & Jun & Jul & Agt & Sep \\
\hline \multirow{2}{*}{ IIA } & Bero & PG/KC dan Ketela & Ketela & \multicolumn{3}{|c|}{ Bero } \\
\hline \multirow{2}{*}{ II C } & Bero & \multicolumn{2}{|c|}{ KE dan Ketela } & Panen & \multicolumn{3}{|c|}{ Ketela } & \multicolumn{3}{|c|}{ Bero } \\
\hline \multirow{2}{*}{ III B } & \multicolumn{3}{|c|}{ PG dan Ketela } & \multicolumn{3}{|c|}{ JG/KE dan Panen } & \multicolumn{3}{|c|}{ Ketela } & \multicolumn{3}{|c|}{ Bero } \\
\hline
\end{tabular}

Sumber: Hasil Analisis Data

\section{PENUTUP \\ Kesimpulan}

Berdasarkan hasil penelitian yang telah dilakukan, maka dapat disimpulkan beberapa hal berikut:

1. Tipe iklim yang terdapat pada kawasan karst Kabupaten Gunungkidul terdiri dari tipe iklim IIA, IIC dan IIIB; dan

2. Pola tanam untuk tipe iklim IIA adalah padi gogo atau kacang dan ketela (Desember-Februari) dan melakukan panen ketela pada Bulan Maret dan April. Pola tanam untuk tipe iklim IIC adalah Kedela dan Ketela (Desember-Februari) dan melakukan panen ketela pada Bulan Maret dan April, sedangkan tipe iklim IIIB dapat melakukan panen sebanyak dua kali dalam setahun, dengan pola tanam padi gogo dan ketela pada Bulan Oktober sampai Januari, dan Jagung atau kedelai pada Bulan Februari sampai April.

\section{Saran}

Terkait dengan berbegai keterbatasan yang ada dalam metode ini, maka berikut beberapa saran dalam menggunakan metode ini:

1. Metode ini tidak cocok untuk wilayah yang telah menggunakan irigasi;

2. Perlu memperhatikan adanya anomali cuaca seperti pengaruh siklon tropis dan ENSO;

3. Perlu disesuiakan dengan analisis kemampuan dan kesesuaian lahan dalam menentukan jenis tanaman. 


\section{DAFTAR PUSTAKA}

Awang, S.A. dan Nurhadi. 2005. Konservasi Sumber Air Tambakromo: Ketersediaan dan Kelangkaan Air. dalam Awang, S.A. 2005. Kelangkaan Air: Mitos Sosial, Kiat dan Ekonomi Rakyat. Yogyakarta: Debut Press.

Balai Penelitian Agroklimat dan Hidrologi, Departemen Pertanian Republik Indonesia. 2007. Atlas Sumberdaya Iklim Pertanian Indonesia. Diakses $\begin{array}{lllll}\text { pada } & \text { Tanggal } & 27 & \text { Oktober } & 2011\end{array}$ http://pustaka.litbang.deptan.go.id/publikasi/wr266045.pdf

Cahyadi, A.; Nucifera, F.; Marfai, M.A. dan Rahmadana, A.D.W. 2012. Perencanaan Penggunaan Lahan di Kawasan Karst Berbasis Analisis kemampuan Lahan dan Pemetaan Kawasan Lindung Sumberdaya Air (Studi Kasus di Kecamatan Ponjong, Kabupaten Gunungkidul, D.I. Yogyakarta). Prosiding Seminar Nasional Science, Engineering and Technology, 23-24 Februari 2012. Program Magister dan Doktor Fakultas Teknik Universitas Brawijaya, Malang.

Eiche, E.; Haryono, E.; Federkeil, M.; Natscher, V.; Mangini, A.; Neumann, T.; Hochschild, M. 2011. $\delta^{18} 0 / \delta^{13} \mathrm{C}$ Records and Trace Element Ratios of Two Stalagmites from Gua Bribin, Java, Indonesia - Indications of The Paleoclimatic History of Southern Java. Makalah dalam Asian TransDisciplinary Karst Conference 2011. Fakultas Geografi Universitas Gadjah Mada Yogyakarta, 7-10 Januari 2011.

Krisnohadi, A. 2011. Tekanan Penduduk dan Trend Perubahan Penggunaan Lahan Potensial untuk Pertanian di Kota Singkawang Kalimantan Barat. Prosiding Seminar Nasional Budidaya Pertanian. 7 Juli 2011. Bengkulu. Muta'ali, L. 2012. Daya Dukung Lingkungan untuk Perencanaan Pengembangan Wilayah. Yogyakarta: Badan Penerbit Fakultas Geografi (BPFG) Universitas Gadjah Mada.

Nurjani, Emilya; Adji, Tjahyo Nugroho; Hardjo, Slamet Karen; dan Cahyadi, Ahmad. 2011. Inventarisasi Potensi Sumberdaya Air di Desa Wukirsari Kecamatan Cangkringan untuk Menentukan Solusi Alternatif Akibat Kerusakan Jaringan Irigasi oleh Banjir Lahar Pasca Erupsi Gunungapi Merapi 2010. Laporan Penelitian. Sekolah Vokasi Universitas Gadjah Mada.

Sartohadi, J. dan Putri, R.F. 2008. Evaluasi Potensi Degradasi Lahan dengan Menggunakan Analisa Kemampuan Lahan dan Tekanan Penduduk Terhadap Lahan Pertanian di Kecamatan Kokap Kabupaten Kulon Progo. Forum Geografi, Vol. 22 (1). Hal: 1-12.

Sudarmaji; Suprayogi, Slamet dan Setiadi. 2012. Konservasi Mataair

Berbasis Masyarakat di Kabupaten Gunungkidul. Yogyakarta: Sekolah Pascasarjana Universitas Gadjah Mada. 
Sunkar, A. 2008. Deforestation and Rocky Desertification Processes in Gunung Sewu Karst Landscape. Media Konservasi Vol. 13, No. 3 Desember 2008. Hal : $1-7$.

Suryanti, E.D.; Sudibyakto, dan Baiquni, M. 2010. Strategi Adaptasi Ekologis Masyarakat di Kawasan Karst Gunungsewu dalam Mengatas Bencana Kekeringan. Jurnal Kebencanaan Indonesia, Vol. 2(3). Hal: 658-673.

Worosuprojo, S.; Suyono; Risyanto; Adji, T.N. 1997. Kajian Ekosistem Karst di Kabupaten Gunungkidul Provinsi Daerah Istimewa Yogyakarta. Laporan Penelitian. Biro Bina Lingkungan Hidup Provinsi Daerah Istimewa Yogyakarta dan Fakultas Geografi Universitas Gadjah Mada.

Makalah ini merupakan salah satu chapter dalam buku berjudul "Ekologi Lingkungan Kawasan Karst Indonesia: Menjaga Asa Kelestarian Kawasan Karst Indonesia", dengan Editor Sudarmadji, Eko Haryono, Tjahyo Nugroho Adji, M. Widyastuti, Rika Harini, Emilya Nurjani, Ahmad Cahyadi, Henky Nugraha. Buku ini diterbitkan di Yogyakarta Tahun 2013 oleh Penerbit Deepublish. Makalah ini dimuat di halaman 50-58. 